\title{
OPTIMISATION OF TRANSITION AREAS BETWEEN BALLASTLESS TRACK AND BALLASTED TRACK IN THE AREA OF THE TUNNEL TURECKY VRCH
}

The paper follows previously published papers in Communications - Scientific Letters of the University of Zilina No. 4/2014, No. 4/2015 and No. 4/2016, where were presented the results of the diagnostics of the track geometry of the experimental sections surrounding the portals of a new building of the Tunnel Turecky vrch. Based on the data obtained by comprehensive diagnostics, there can be stated that the problematic section in the slab track are the transition areas allowing the transfer of the vehicle between the line structures with a different bending stiffness. The comprehensive diagnostics was realised by the continuous method (measuring trolley KRAB), the results of which were verified by the results of the measuring car of ZSR and by the geodetic monitoring of the layout of the track, as well. Mathematical modelling of the transition areas was realized in the environment of the software ANSYS with the aim to optimise the structural solution of the existing transition areas, as well as of in the future built ones, within the modernization of the railway infrastructure of the Slovak Republic. The model of the existing transition area was structurally optimised-models were realised with application of the stiffening rails and with usage of the under sleeper pads. The model of the current state and the models of the optimised structural solutions of the transition areas were subsequently compared by the values of the vertical displacement, vertical speed and vertical acceleration.

Keywords: railway track, railway superstructure, ballastless track, ballasted track, numerical modelling of transition area

\section{Introduction}

Until now, the track layout and the track geometry parameters have been monitored nine times with the time interval of 6 months in the area of the portals of the Tunnel Turecky vrch. The monitoring was carried out within the comprehensive diagnostics with a continuous method by a manual measuring trolley $K R A B^{T M}$ Light. There was an initial measurement prior to the construction commissioning (MSO) and eight operational measurements (PO1, PO2, PO3, PO4, PO5, PO6, PO7 and PO8). The quality mark with the worst development tendency seems to be the quality mark of the vertical profile of the lines VP, VL $\mathrm{QM}_{\mathrm{VK}}$ based on measurements implemented thus far. A problematic section is, in the long term, the transition area from the slab track (PJD) of the type RHEDA $2000^{\circledR}$ to the ballasted track (the track skeleton is placed into the ballasted trackbed) located on the southern portal of the Tunnel Turecky vrch [1]. The trend lines were created by means of the values VL and VP measured within PO5, PO6, PO7 and PO8 in the section of the transition from the slab track to the ballasted track. Based on these trend lines, it can be assumed that the maintenance limit $( \pm 6 \mathrm{~mm})$ of the parameter VL was expected to be reached approximately in 9/2017 and of the parameter VP will be reached in 5/2018 in the section of the track Nr. 1 in the southern portal of the tunnel. In the track Nr. 2 in the southern portal of the tunnel the values of the maintenance limit of the VL and VP parameters were expected to be reached approximately in 9/2017, or cca. in 6/2018, respectively, [2]. These overrun levels of the maintenance limits were detected within the third measurement campaign of the measuring trolley of the
ZSR (in the autumn of 2017). The trend lines of the other quality marks do not indicate any necessity of the corrective action in the coming years and the parameter values seem to be more or less stabilised. The local defects were recorded within the safety limits before the installations of the sections. Specifically, there were the sections with the slab track (9 local defects), with the ballasted track ( 30 local defects) and in the transition area of the track Nr. 2 in the southern portal (1 local defect). Those defects were removed prior to installation of the sections. This was also verified by the results of the measurement PO1 within which no local defects were recorded. The local defects were recorded in the transition area of the track Nr. 1 in the southern portal (2 local defects in the measurement PO2 and 4 local defects in the measurements $\mathrm{PO} 3$ and PO4) within the other operational measurements. After the executions of the corrective actions, no other local defects were recorded [3].

The railway infrastructure manager has provided so far the results from eleven measurement campaigns of the measuring trolley. The campaigns were executed in the years 2013 (in summer and autumn), 2014 (in spring, summer and autumn), 2015 (in spring, summer and autumn) and 2016 (in spring, summer and autumn). On the measurement results in the sections with the slab track one can the recurrence of the defect of the longitudinal elevation deviation of the left (VL) and the right line (VP) in the section 1.1 (track Nr. 1 of the southern portal of the tunnel) and the defects of the longitudinal elevation deviation of the left line VL in the section 2.2 (track Nr. 2 of the northern portal of the tunnel). The defects of the longitudinal elevation deviation of the left (right) line VL, VP were recorded in the track Nr. 2 of the

\footnotetext{
* ${ }^{1}$ Libor Izvolt, ${ }^{2}$ Jozef Harusinec, ${ }^{1}$ Michal Smalo

${ }^{1}$ Department of Railway Engineering and Track Management, Faculty of Civil Engineering, University of Zilina, Slovakia

${ }^{2}$ Department of Transport and Handling Machines, Faculty of Mechanical Engineering, University of Zilina, Slovakia

E-mail: libor.izvolt@svf.uniza.sk
} 
transition area of the southern portal of the tunnel (section 2.1). The direction fault of the left line SL in the transition area of the adjacent track Nr. 1 (section 1.1) has been detected once so far. In the area of the northern portal of the tunnel in the transition area of the track Nr. 1 defects of the longitudinal elevation deviation VL, VP were recorded in both lines, [4].

The measurements of the track layout (geodetic surveying) have been realised 6 times so far - the initial measurement in the autumn of 2012, the second measurement in the spring of 2013 , the third measurement in the autumn of 2013, the fourth measurement in the spring of 2014, the fifth measurement in the spring of 2015 and the sixth measurement in the spring of 2016. The outputs of the geodetic monitoring of the track proved the results of the comprehensive diagnostics by the continuous method and the results acquired from the measuring trolley of ZSR, as well. Based on the implemented analysis of the measurements, it can be stated that no significant changes in the horizontal or vertical profile of both lines in the section with the slab track were recorded. The same applies also for the slab track where rest the particular rails. The recorded lateral or longitudinal displacements of the track are within the specified measurement accuracy. The lateral displacements of both tracks, within the range from 0 to $12 \mathrm{~mm}$ in the area of the southern portal and from 15 to $20 \mathrm{~mm}$ in the area of the northern portal of the tunnel, were diagnosed in the same section with the ballasted track [5].

The diagnostics by a visual method of the sections with the slab track was realised in the summer of 2015 and the size of the cracks in the reinforced concrete plate of the slab track and in the reinforced concrete blocks was documented. The results of this diagnostics were compared to the documentation of the railway infrastructure manager processed based on the diagnostics realised in the autumn of 2012 and in the spring of 2013. The highest frequency of cracks was detected in the section of the track Nr. 2 of the northern portal of the tunnel in the area between the railway bridge and the transition area. Based on the comparison to the results of 2013 , it is obvious that the extent and amount of the cracks do not show any changes. In the section with the highest frequency of cracks no significant deviations by the measuring trolley $K R A B^{T M}$-Light, measuring car and neither by the geodetic monitoring were measured.

Based on evaluation of measurements of the track geometry and the layout of the track, it can be stated that the monitored sections with the slab track are stabilised and that they do not show any relevant changes of the particular parameters between the individual measurements. The sections with the ballasted track do show changes; however, those changes result from the character of this construction. The ballasted track has the higher stiffness values in comparison to the slab track. Therefore, the ballasted track needs the adjustment of the track geometry, cleaning and supplement with the ballast material and other maintenance and repair works in certain intervals (depending on the operational load) with the aim to maintain the quality parameters throughout the life span of the track. However, the measurements of the track geometry pointed to the irregularities in the transition areas between the ballasted track and the slab track, especially in both of the tracks in the area of the southern portal of the Tunnel Turecky vrch. These results were subsequently proved by the geodetic survey and also by the outputs of the measuring trolley. The decreases recorded in these transition areas, from the beginning of the measurements, resulted in the limit overruns of the vertical profile quality marks of the rails $\mathrm{VP}, \mathrm{VL} \mathrm{QM}_{\mathrm{VK}}$, as well as in the appearance of the local defects. Based on these facts, the railway infrastructure manager executed the corrective action. The corrective action slightly slowed down the tendencies of the defect development; however, the track geometry quality of both lines is still being reduced. As it was expected, the next limit overrun occurred during the second half of the year 2017 and resulted in the necessity to execute another corrective action.

The transition areas, between the ballasted track and the slab track in the railway infrastructure of the Slovak Republic, have been for the first time exposed to such difficult conditions (the operational load in combination with the passenger train speeds up to $160 \mathrm{kmph}$ ) especially in the area of the portals of the Tunnel Turecky vrch. The other operated transition areas, e.g. in the area of the portals of Bratislava tunnels Nr. 1 and Nr. 2, are also exposed to a high operational load, however, in combination with significantly lower train speeds (and by that also significantly lower dynamic forces affecting the transition area construction). There is the expectation that the other sections with the slab track will be built within the modernization of the railway network of the Slovak Republic. Therefore, it would be convenient to improve the further adjusted transition areas structurally and, in this way, to eliminate the defects formation in the track geometry. This will exclude or at least eliminate the corrective actions on the exposed track sections (bridge structures, tunnels). The engineers, who currently work on the projects of modernisation of the railway infrastructure of ZSR in Slovakia, normally design those constructions at the exposed track sections.

\section{The numerical modelling of the transition areas}

The numerical modelling was realised with the aim to structurally optimise the transition areas. The modelling was based on the faults and defects occurrence in the transition areas from the slab track to the ballasted track recorded within the diagnostics of the monitored sections in the areas of the portals of the Tunnel Turecky vrch (especially in the area of the southern portal). The optimisation of the construction solution of the transition areas was realised to enhance the continuity of the vehicle transfer between the two construction systems of the railway with different stiffness. In this way, the assumptions will also be created for elimination or minimisation of the extent of fault and defect formation in the transition areas and their immediate surrounding.

In the case of the ballasted track the wheel forces are transferred from the rail through the sleeper to the track ballast and the subgrade. Zimmermann [6] introduced a model of calculation for the specification of the rail lowering, which is based on the elastic embedded longitudinal beam. This beam reacts to the track ballast and the sub-ballast on all the sleepers as to springs of the same size and independent from each other, which are characterized by means of the modulus of subsoil reaction $C$. The bending coefficient of the sleeper support $C$ depends on the rail lowering and surface pressure between the sleeper and the track ballast. It is expressed by the formula [7]: 
$C=\frac{p}{z}\left(\mathrm{~N} \cdot \mathrm{mm}^{-3}\right)$

where:

$C$ - bending coefficient of the sleeper support, $\left(\mathrm{N} . \mathrm{mm}^{-3}\right)$,

$p$-surface pressure between the sleeper and the ballasted trackbed, $\left(\mathrm{N} . \mathrm{mm}^{-2}\right)$ and

$z$ - rail lowering, $(\mathrm{mm})$.

Modulus of the subsoil reaction is determined from the measurements of the rail lowering under the static load by a wheel (wheel power) in accordance with the formula:

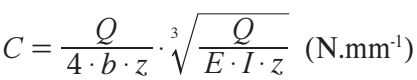

where:

$Q$ - the wheel force, $(\mathrm{N})$,

$E$ - modulus of elasticity, (N.mm²),

$I$ - moment of inertia of the rail, $\left(\mathrm{mm}^{4}\right)$,

$b$ - fictional width of the elastic embedded longitudinal beam, $(\mathrm{mm})$, whereby

$b=\frac{F}{a}\left(\mathrm{~N} \cdot \mathrm{mm}^{-1}\right)$

where:

$F$ - half efficient bottom surface of the sleeper, $(\mathrm{mm} 2)$ and

$a$ - axial distance of the sleepers, (mm).

For the railway track with the long-term operation the modulus of subsoil reaction is ranging from 0.05 up to 0.15 $\mathrm{N} . \mathrm{mm}^{-3}$. For the new buildings, the value of the modulus of subsoil reaction is considered to range from 0.3 up to $0.4 \mathrm{~N} \cdot \mathrm{mm}^{-3}$ [7].

In the case of the slab track, the consolidated (bonded) and unconsolidated bearing layers contribute to the elasticity with only a small portion. Therefore, in the model-based calculation, as the elastic components are considered only the resilient pads (a part of the rail fixing placed under the rail). The resilient pads enter the calculation with the so-called stiffness of the fixing node $c$, which is being calculated from the formula:

$c=\frac{S}{z}\left(\mathrm{~N} \cdot \mathrm{mm}^{-1}\right)$

where:

$S$ - force acting on the fixing node, $(\mathrm{N})$.

Unlike for the ballasted track, with a layer of the ballasted trackbed, for the slab track is instead of the modulus of subsoil reaction $C$ used the stiffness of the fixing node $c$. For the relationship between the modulus of the subsoil reaction $C$ and the stiffness of the fixing node $c$ applies the following formula:

$C=\frac{S}{F \cdot z}=\frac{c}{F}\left(\mathrm{~N} \cdot \mathrm{mm}^{-3}\right)$

where:

$F$ - half efficient bottom surface of the sleeper, $\left(\mathrm{mm}^{2}\right)$.

The static track stiffness $c_{G}$ is unlike for the stiffness of the fixing node $c$ not defined by means of the force acting on the fixing node, but by means of the static wheel force $Q$. The track stiffness is calculated in accordance with the formula:

$c_{G}=\frac{Q}{z}\left(\mathrm{~N} \cdot \mathrm{mm}^{-1}\right)$ where:

$c_{G}$ - the static track stiffness, $\left(\right.$ N.mm $\left.{ }^{-1}\right)$.

After substituting Equation (4) and Equation (5) into the Equation (2), one obtains the formula for the relation between the stiffness of the fixing node $c$ and the track stiffness $c_{G}$ for the slab track:

$c_{G}=\sqrt[4]{\left(\frac{4 \cdot c}{a}\right) \cdot E \cdot I}\left(\mathrm{~N} . \mathrm{mm}^{-1}\right)$

The dimensioning of the slab track is being carried out with the aim to ensure the sufficient elasticity of the track form. The tests have shown that the rail lowering $z$ with approximately $1.5 \mathrm{~mm}$ and the static track stiffness $c_{G}$ of the value $64 \pm 5 \mathrm{kN} \cdot \mathrm{mm}^{-1}$ correspond most closely to this objective.

The formula for the modulus of subsoil reaction $C$ and the track stiffness $c_{G}$ for the ballasted track is obtained by inserting the Equation (6) into the Equation (2):

$c_{G}=\sqrt[4]{64 \cdot E \cdot I \cdot b^{3} \cdot C^{3}}\left(\mathrm{~N} . \mathrm{mm}^{-3}\right)$

If the Equation (6) for the stiffness of the fixing node $c$ is adjusted, one obtains:

$c=\sqrt[3]{\frac{c_{G}^{4} \cdot a^{3}}{64 \cdot E \cdot I}}\left(\right.$ N.mm $\left.\mathrm{mm}^{-1}\right)$

Both construction systems - the conventional track (the so-called ballasted track), as well as the slab track (the so-called ballast-free track), are the structures proved by operation during decades. The transition areas represent the potentially problematic places in the line structure where, in general, every change in construction can result in change of its dynamic load. The increase of the dynamic load directly influences the track position and most often results into the rail lowering which increases over time.

The initial (comparing) model for the realization of the numerical modelling is the transition area without any components - so the transit from the slab track directly to the ballasted track (model A). Another stage of the numerical modelling was creation of the transition area model in the surrounding of the southern portal of the Tunnel Turecky vrch. The transition area is created as a reinforced concrete tub of the concrete C 30/37, $20 \mathrm{~m}$ long, longitudinally graded and covered with an elastic mat (model B). The thickness of the ballast bed in this type of transition area, is decreasing under the sleepers in the direction to the slab track, whereby the stiffness of the trackbed is gradually increasing. The last stage of the process of the numerical modelling was the creation of the models optimising the transition area applied in the surrounding of the southern portal of the Tunnel Turecky vrch by adding other structural elements. Those were:

- Two stiffening rails (profile 49E1) $20 \mathrm{~m}$ long. The rails are placed in the length of $5 \mathrm{~m}$ in the slab track section and in the length of $15 \mathrm{~m}$ in the ballasted track section - model C.

- Under sleeper pads Sylomer SLB 2210 G (producer Getzner) $10 \mathrm{~mm}$ thick. They are placed in the transition tub directly behind the slab track, in the section with the length that the fastest train passes in $0.5 \mathrm{~s}$. This, at speed of $160 \mathrm{kmph}$, represents the section $22.2 \mathrm{~m}$ long. The pads, based on recommendations from the supplier, were used in the length 
Table 1 Three-dimensional models for monitoring of the dynamic behaviour of different types of transition areas

\begin{tabular}{|c|c|}
\hline Model definition & Transition area solution \\
\hline $\begin{array}{l}\text { Model A } \\
\text { (initial model) }\end{array}$ & - $\quad$ without any transition area (the direct transfer of the vehicle from the slab track to the ballasted track) \\
\hline $\begin{array}{l}\text { Model B } \\
\text { (current state) }\end{array}$ & $\begin{array}{l}\text { - } 20 \mathrm{~m} \text { long reinforced concrete tub with the longitudinal gradient (the track ballast of variable thickness) } \\
\text { covered by the elastic mat }\end{array}$ \\
\hline Model C & $\begin{array}{l}\text { - } 20 \mathrm{~m} \text { long reinforced concrete tub with the longitudinal gradient (the track ballast of variable thickness) } \\
\text { covered by the elastic mat and }\end{array}$ \\
\hline (current state + two stiffening rails) & $\begin{array}{l}\text { - two stiffening rails (profile 49E1), } 20 \mathrm{~m} \text { long, placed in the length of } 5 \mathrm{~m} \text { in the slab track section and in } \\
\text { the length of } 15 \mathrm{~m} \text { in the ballasted track section }\end{array}$ \\
\hline $\begin{array}{l}\text { Model D } \\
\text { (current state + under sleeper pads } \\
\text { in the transition tub) }\end{array}$ & $\begin{array}{l}\text { - } 20 \mathrm{~m} \text { long reinforced concrete tub with the longitudinal gradient (the track ballast of variable thickness) } \\
\text { covered by the elastic mat and } \\
\text { application of the under sleeper pads Sylomer SLB } 2210 \mathrm{G}, 10 \mathrm{~mm} \text { thick, placed in the whole length of } \\
\text { the transition area }(20 \mathrm{~m})\end{array}$ \\
\hline $\begin{array}{l}\text { Model E } \\
\text { (current state + under sleeper pads } \\
\text { partially in the slab track section } \\
\text { and partially in the transition } \\
\text { area constructed in the reinforced } \\
\text { concrete tub) }\end{array}$ & $\begin{array}{l}\text { - } 20 \mathrm{~m} \text { long reinforced concrete tub with the longitudinal gradient (the track ballast of variable thickness) } \\
\text { covered by the elastic mat and } \\
\text { application of the under sleeper pads Sylomer SLB } 2210 \mathrm{G}, 10 \mathrm{~mm} \text { thick, placed in the section } 22.2 \mathrm{~m} \\
\text { long, whereby the half of the section length is on the slab track ( } 11.1 \mathrm{~m}-18 \text { sleepers) and the half of } \\
\text { the section length is in the transition section in the shape of the reinforced concrete tub (11.1 m - } 18 \\
\text { sleepers) }\end{array}$ \\
\hline
\end{tabular}

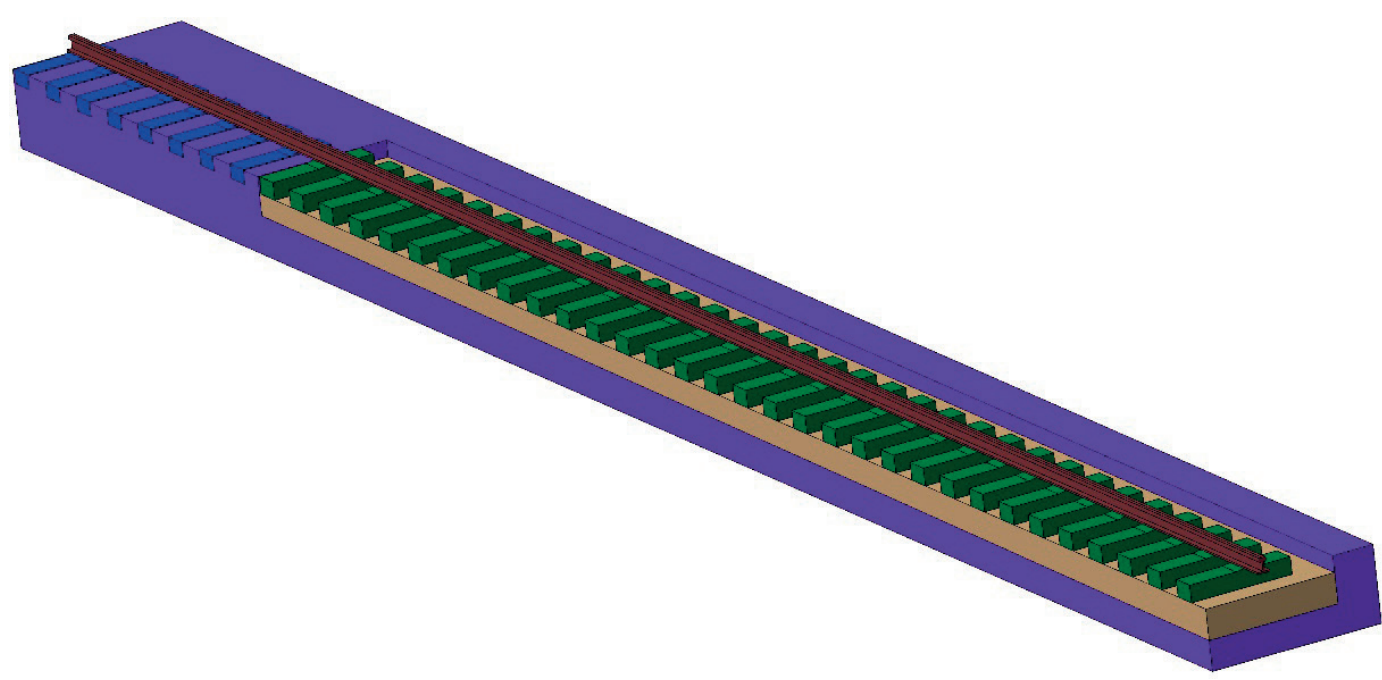

Figure 1 Model of the transition area with the reinforced concrete tub in the program CATIA

of $20 \mathrm{~m}$ (i.e. in the whole length of the transition area) model D.

- Under sleeper pads Sylomer SLB 2210 G (producer Getzner) $10 \mathrm{~mm}$ thick. They are placed in the slab track section and in the transition area in the shape of the reinforced concrete tub directly behind the slab track in the section with the length that the fastest train passes in $0.5 \mathrm{~s}$. This, at speed of $160 \mathrm{kmph}$, represents the section $22.2 \mathrm{~m}$ long. The section was divided into two parts of the same length. The first part is situated in the section with the slab track $(11.1 \mathrm{~m}-18$ sleepers) and the second one in the transition area (in the reinforced concrete tub) immediately behind the slab track (11.1 m - 18 sleepers). The technical and technological possibilities of the installation of the under sleeper pads into the slab track are to be consulted with the supplier of the slab track system - model E.

During the application process of the under sleeper pads, the supplier of the pads of the producer Getzner - the company Hydrobeton, Ltd was consulted.
Initially, the aim of the numerical modelling was the modelling of the transition area with the stabilization of the railway ballast by chemical binders, as well. However, because of the large variation of the input data values, the numerical modelling was finally not realised since the relevance of the comparisons to other numerical models was questionable.

The overview of the numerical models for monitoring of the dynamic behaviour of different types of transition areas is introduced in Table 1.

The numerical modelling of the transition areas was carried out by means of the three-dimensional (3-D) models A, B, C, D and $\mathrm{E}$ created in the program CATIA V5-6R2016 (Figure 1) based on the two-dimensional drawings from the program Auto $C A D$ 2016. The individual models were subsequently transferred into the working environment of the program ANSYS R17.2. by means of the exchange files STEP.

The models were initially implemented as the model of the $20 \mathrm{~m}$ long section with the slab track, the $20 \mathrm{~m}$ long transition area (with the exception of the model without the transition 
Table 2 Material characteristics of the line structure elements

\begin{tabular}{|c|c|c|c|}
\hline Line structure element & $\begin{array}{c}\text { Volume weight } \\
\qquad\left(\mathrm{kg} \cdot \mathrm{m}^{-3}\right)\end{array}$ & $\begin{array}{l}\text { Young Modulus } \\
\qquad(\mathrm{GPa})\end{array}$ & $\begin{array}{c}\text { Poisson's ratio } \\
(-)\end{array}$ \\
\hline Rail & 6186 & 210 & 0.3 \\
\hline Rail pad & 950 & 0.21 & 0.3 \\
\hline Under sleeper pad & 4200 & 1.3 & 0.42 \\
\hline Sleeper (in the section with the track ballast) & 2054 & 30 & 0.2 \\
\hline Double block sleeper (in the slab track section) & 2400 & 70 & 0.2 \\
\hline Track ballast & 1800 & 0.2 & 0.1 \\
\hline Material of the sub-ballast layer & 2200 & 0.3 & 0.2 \\
\hline Embankment material (in the section with the ballasted track) & 2200 & 0.4 & 0.2 \\
\hline Concrete bearing layer (CBL) & 2400 & 34 & 0.2 \\
\hline Hydraulically bound bearing layer (HBL) & 2400 & 5 & 0.2 \\
\hline Frost protection layer (FPL) & 2400 & 0.12 & 0.2 \\
\hline
\end{tabular}

Table 3 Results of the static load tests in the area of the southern portal of the tunnel

\begin{tabular}{|c|c|c|c|c|c|}
\hline $\mathrm{Km}$ position & Structural part & $\begin{array}{l}\text { Characteristic of the permanent way } \\
\text { construction }\end{array}$ & Track number & $\begin{array}{c}\text { Value of the static } \\
\text { deformation modulus } \\
\mathrm{E}_{\mathrm{s}, \mathrm{i}}(\mathrm{MPa})\end{array}$ & $\begin{array}{c}\text { Degree of } \\
\text { compaction } \\
\mathrm{E}_{\text {def2 }} / \mathrm{E}_{\text {def } 1}\end{array}$ \\
\hline \multirow[t]{2}{*}{102.365} & Subgrade & Ballasted track & 2 & 225.0 & 4.33 \\
\hline & Subgrade & Ballasted track & & 250.0 & 3.50 \\
\hline \multirow[t]{2}{*}{102.375} & $\begin{array}{l}\text { Top surface of the sub- } \\
\text { ballast }\end{array}$ & Ballasted track & 1 & 75.0 & 3,60 \\
\hline & Ballast bed & Ballasted track & & 93.8 & 3.30 \\
\hline 102.425 & Subgrade & Ballasted track & 1 & 173.1 & 3.00 \\
\hline 102.465 & Ballast bed & Transition area & 1 & $22.0^{1)}$ & 1.67 \\
\hline \multicolumn{6}{|c|}{ Note: } \\
\hline
\end{tabular}

area) and the $20 \mathrm{~m}$ long ballasted track section. At the start of tackling the issue was presumed that one of the problems can be the insufficient length of the transition area whereas the foreign regulations, e.g. [8], recommend the length of the transition area in accordance with the formula:

$$
L_{\min }=0.5 \cdot \frac{V_{\max }}{3.6}(\mathrm{~m})
$$

where:

$L_{\min }$ - minimum recommended length of the transition area, (m) and

$V_{\max }$ - maximum speed in the section, $\left(\mathrm{km} \cdot \mathrm{h}^{-1}\right)$.

The transition areas in the surrounding of the portals of the Tunnel Turecky vrch should have, according to Equation (10), the length minimum $22.2 \mathrm{~m}$ for the line speed of $160 \mathrm{kmph}$. This means that the transition areas are $2.2 \mathrm{~m}$ shorter than the ones recommended by the foreign regulations. However, in the course of tackling the issue, it was proved that the increased length of the transition area, e.g. to the length of $25 \mathrm{~m}$, would bring no or only a negligible improvement. Therefore, the numerical modelling of the transition areas with an optimised length was not realised. The numerical modelling concentrated on the optimisation of the critical place of the transition areas - the place of the end of the slab track and the beginning of the transition area.
Due to the challenge and the long time needed to launch each of the models and also in view of the fact that there occurred no significant deviations of the values in the section with the slab track and the part of the transition area in the shape of the reinforced concrete tub (circa $15 \mathrm{~m}$ ) adjacent to the ballasted track, the model length was reduced. The model was ca. $5 \mathrm{~m}$ long section with the slab track and the transition area in the whole length. That was especially the place of the end of the slab track and the beginning of the transition area that proved to be crucial. For that reason, the shortening of the model length did not have any influence on the result of the numerical modelling of the transition areas concerned.

Each model was implemented only for one rail on which the wheel of the railway vehicle moves. Since this is a symmetrical problem and the railway line is in a direct section and without any super elevation, there was no point in realization of the model on the track as a whole. The so called "mirroring"” of the model would cause the increase in the number of nodes, elements and couplings, and logically also the extension of mathematical calculations, in connection with the slowing-down the numerical modelling process.

Each model was simultaneously made by application of the concerned material characteristics, introduced in Table 2, [9], [10], and the values of the static deformation modulus $E_{s, l}$, which were identified by the static load tests on the particular levels of subsoil of the monitored structure. Those values were acquired 


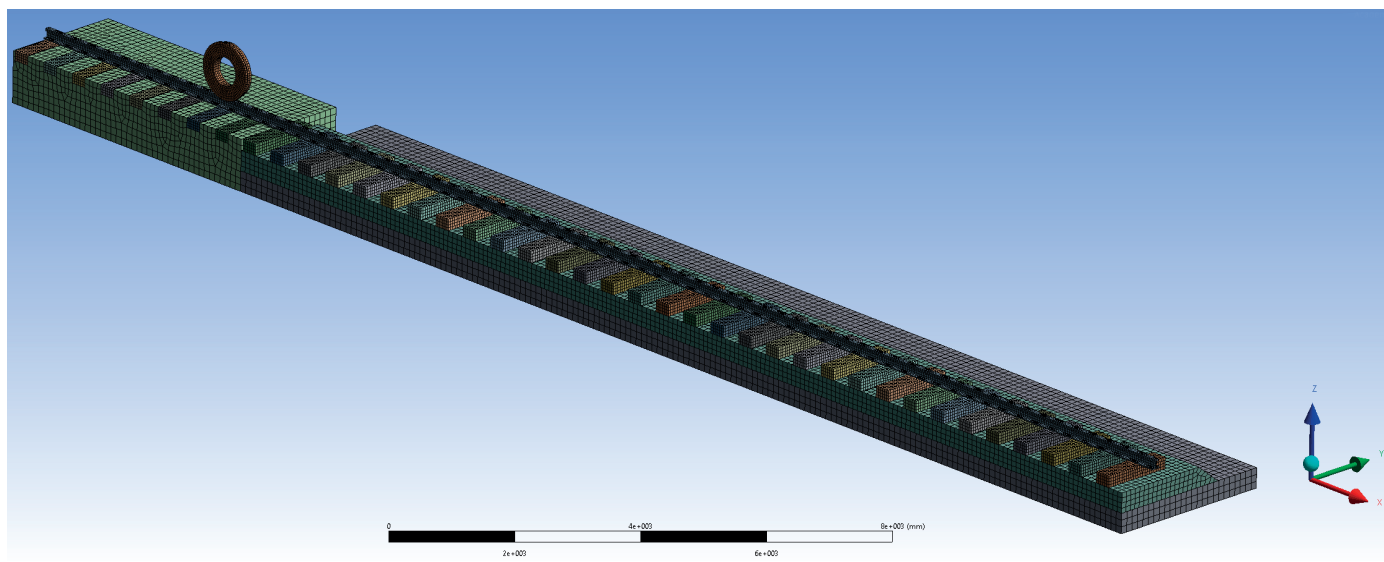

Figure 2 Model A - (initial model)

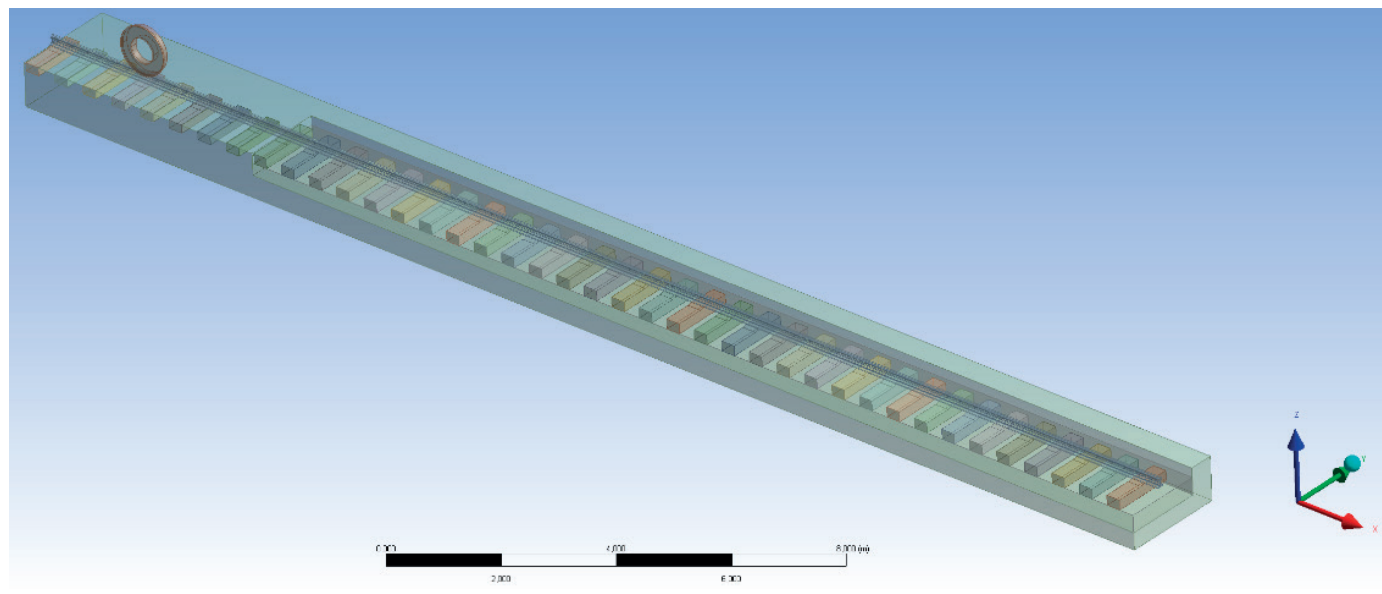

Figure 3 Model B - (current state)

within the quality verification of the realised works during the installation of the modernized line structure, in terms of the methodology of the Regulation by ZSR S4 Subgrade, Appendix No. 20. That diagnostics of the quality of the realised geotechnical works was carried out by the employees of the Department of the Railway Engineering and Track Management during the building of the transition sections in the area of the portals of the Tunnel Turecky vrch. The values of the static deformation modulus $E_{s}$ which were identified by the static load tests, are introduced in Table 3. The values of the static deformation modulus $E_{s, i}$ are linearly interpolated between the places of the measuring for the needs of the numerical modelling.

The model of the transition area in the surrounding of the southern portal of the Tunnel Turecky vrch (model B) comprises of 101369 node points 74598 elements and 129 contact couplings. Each calculation was divided into 120 integration steps. Since this is a non-linear problem, it was necessary to carry out from 337 up to 456 integration steps for each calculation.

For the value of the time interval $t$ is valid (for the vehicle speed $160 \mathrm{kmph}$ ) the formula:

$t=\frac{S}{v}=\frac{0.065}{44.44}=0.0014625 \mathrm{~s}$

\section{where:}

$s$ - length of the iterative step, (m),

$v$ - vehicle speed, $\left(\mathrm{m} \cdot \mathrm{s}^{-1}\right)$,
The value $0.065 \mathrm{~m}$ was chosen as the length of the iterative step. It is considered, that the change of the vertical position parameter on this interval causes the change of the vertical speed. For the value of the vertical speed $v_{z v}$ applies the formula:

$v_{z v}=\frac{z_{n}-z_{n-1}}{t}\left(\mathrm{~m} \cdot \mathrm{s}^{-1}\right)$

where:

$z_{n}$ - vertical displacement in point $\mathrm{n},(\mathrm{m})$,

$z_{n-1}$ - vertical displacement in point $\mathrm{n}-1,(\mathrm{~m})$,

$t$ - time (s).

For the value of the vertical acceleration $a_{z v}$ applies the formula:

$a_{z v}=\frac{v_{z v, n}-v_{z v, n-1}}{t}\left(\mathrm{~m} . \mathrm{s}^{-2}\right)$

where:

$v_{z v n}$ - vertical speed in the point $n,(\mathrm{~m})$,

$v_{z v, n-l}$ - vertical speed in the point $n-1,(\mathrm{~m})$.

Creation of the individual models started by the creation of basic components of the railway line (the rails, fastenings, sleepers, trackbed layers, models of the check rails and under sleeper pads). A separate task was the creation and testing of the effects of the body movement on the rail embedded on the subgrades of different material characteristics and the creation of contact pairs between these materials. The basic objective was to reflect, as closely as possible, the reality of the load transfer. 


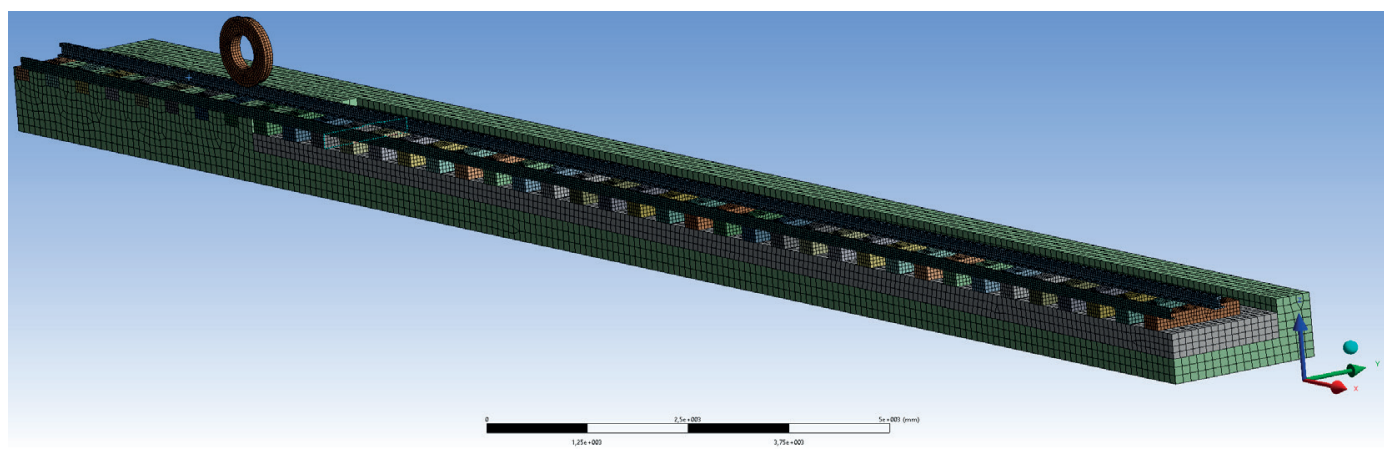

Figure 4 Model C - (current state + two stiffening rails)

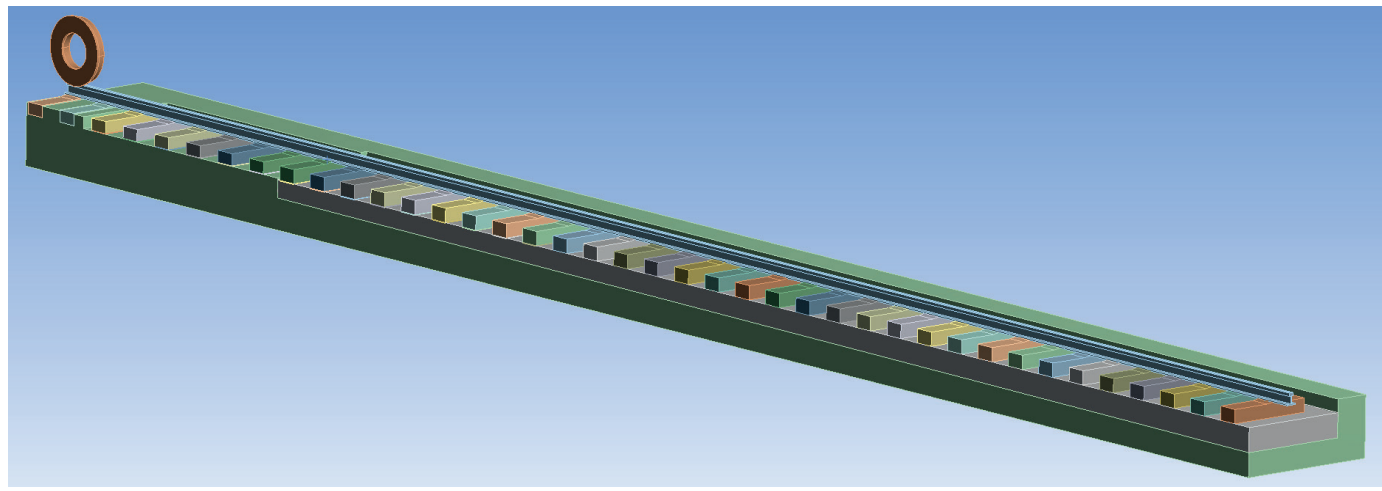

Figure 5 Model D - (current state + under sleeper pads in the transition tub)

Subsequently, the moving wheel was given the vertical power adequate to the axle load (half of the value $225 \mathrm{kN}$ on the axle, so $112.5 \mathrm{kN}$ ), which replaced the original unit force.

A model of the current state - labelled as model B (Figure 3) was gradually created, into which were added other structural elements. $\mathrm{T}$ the model $\mathrm{C}$ was created with the two stiffening rails (Figure 4) and models D and E with application of the under sleeper pads Sylomer SLB 2210 G (Figure 5).

Finally, the transition area from model B was omitted, creating the initial (comparing) model A. This model should serve as a comparison of impairment of the individual parameters, if there is no transition area applied on the line (Figure 2).

\section{Evaluation the numerical modelling results}

Comparison of the results of the numerical modelling was realised by comparison of values of the vertical displacement, vertical speed and vertical acceleration. The graphic presentation of the introduced parameters is depicted in Figure 6, Figure 7 and Figure 8. For better visualisation, the graphs illustrate only a segment of the modelled section where the biggest parameter changes are. They depict the last sleeper of the slab track and the first three sleepers (in case of the vertical displacement the first six sleepers) of the transition area.

The numerical modelling of the transition areas was implemented by the load (wheel) transfer between areas with different stiffness values. The graph area is depicted in such a way that the value 0 of the horizontal axis represents the axis of the last sleeper in the slab track section. For the better visualisation the colour coding was used for the area with the slab track (blue background) and the transition area (white background, with the exception of model A, which is marked out with a chain line and in which behind the slab track follows immediately the ballasted track). For the better orientation, the rail supports (double block sleepers in the section with the slab track as well as the reinforced concrete sleepers in the section with the track ballast) are marked out by a vertical dashed line in each graph.

According to the initial assumption, the worst results are recorded for model A (without the transition area) where the line structure is the most stressed. Significantly better values are depicted on the model of the current state (model B), where the application of the transition tub lowered the values of the vertical displacement and the vertical speed, as well. Unlike the initial assumption, the better results are obtained from the model $\mathrm{C}$ (with a couple of stiffening rails). In that case, an improvement of the values compared to model B was recorded, but only a minimal one. As an appropriate solution, based on the carried out numerical modelling, seems to be the application of the under sleeper pads Sylomer SLB $2210 \mathrm{G}$. These under sleeper pads reduced the values of the virtual displacement and also the virtual speed in both numerical models (models D and $\mathrm{E}$ ) in comparison to the current state (model B), as well as compared to the model of the current state improved by the application of the stiffening rails (model $\mathrm{C}$ ). Model $\mathrm{E}$ seems to be optimal, as the transition between the slab track and the transition area is the most fluent for all the three monitored parameters.

\section{Conclusion}

The three-dimensional models, created for monitoring of the dynamic behaviour of different types of the transition areas from the slab track to the ballasted track, are by means of the 


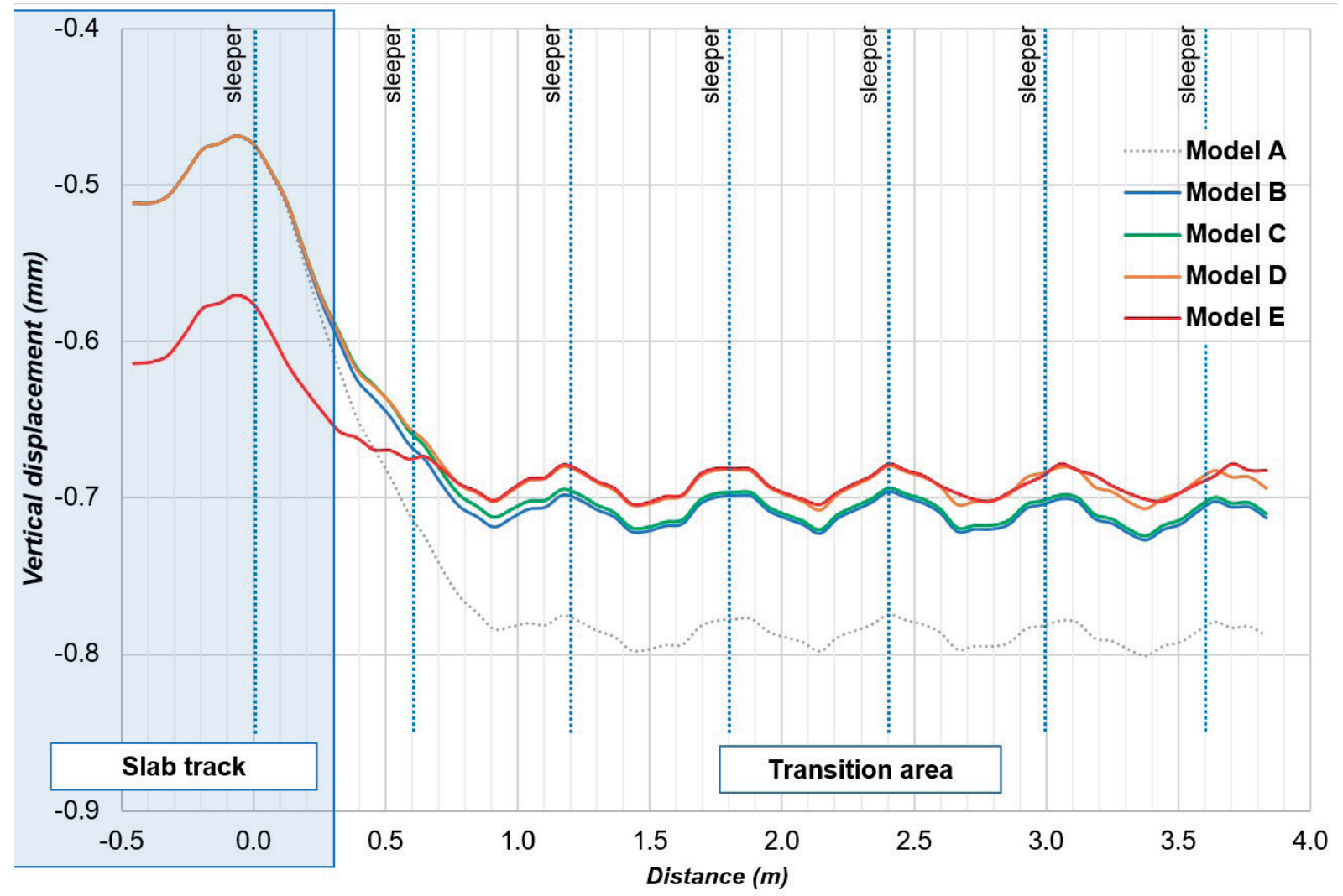

Figure 6 Vertical displacement - model comparison

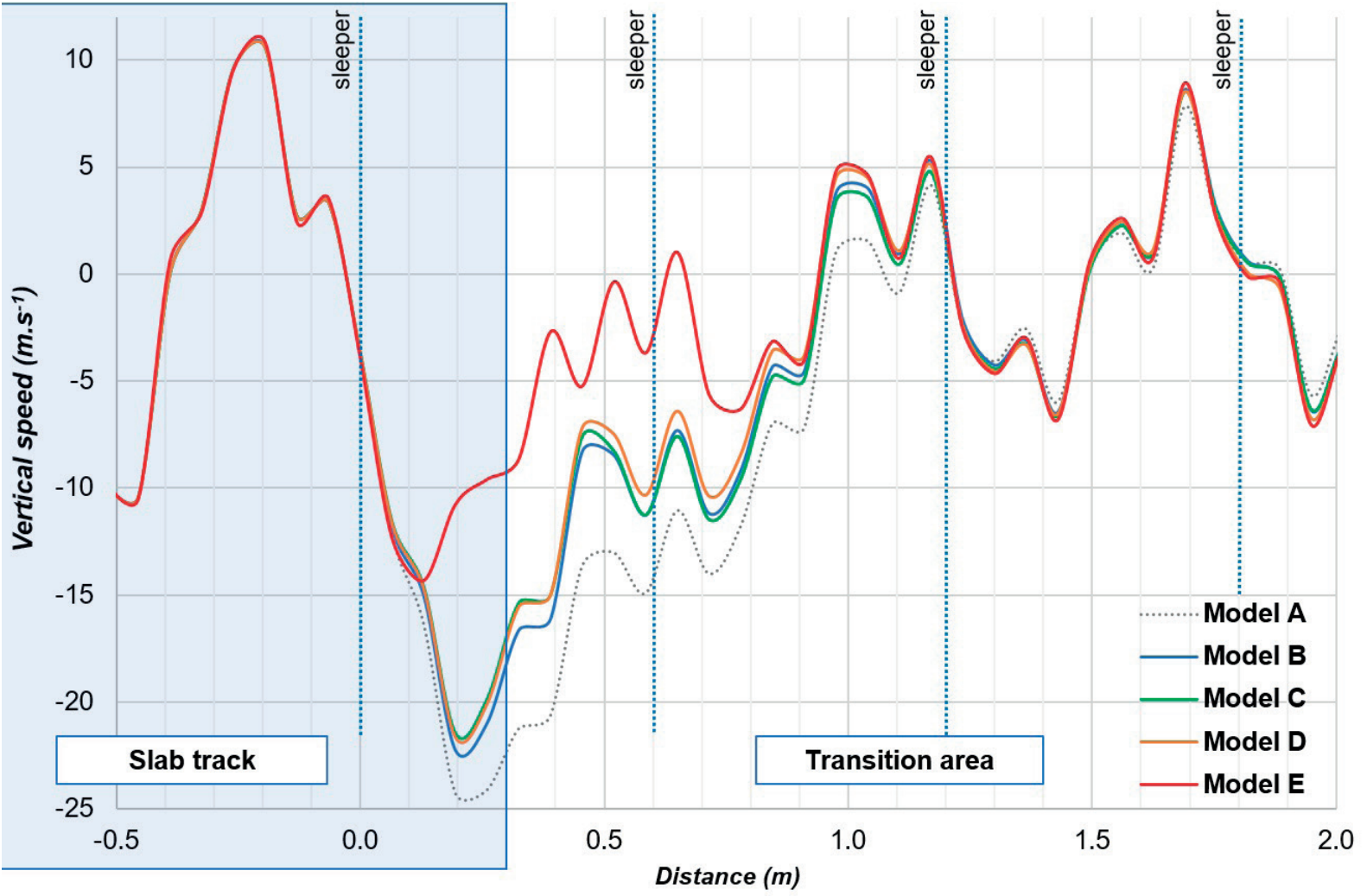

Figure 7 Vertical speed-model comparison 


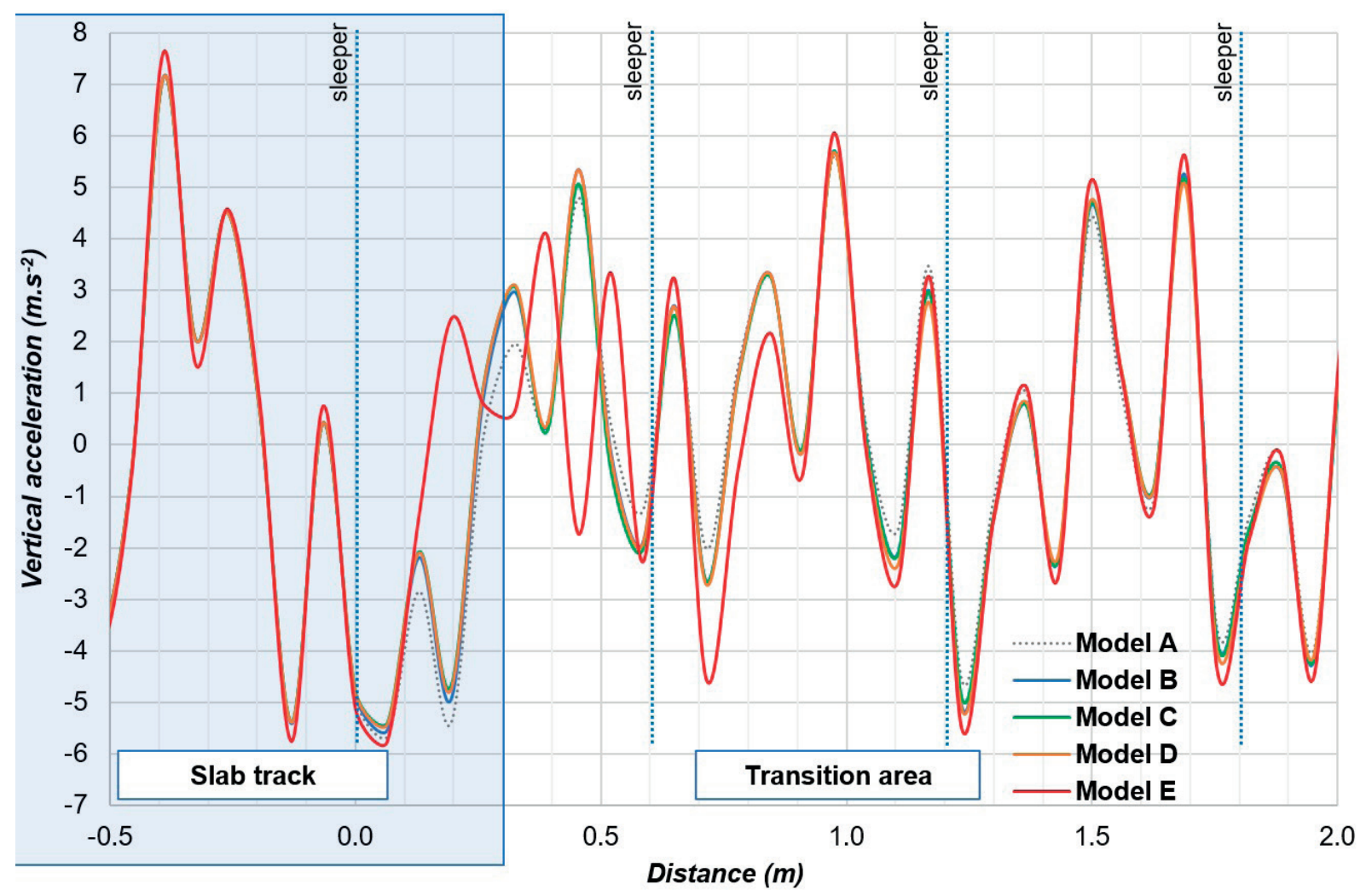

Figure 8 Vertical acceleration - model comparison

numerical modelling confronted to each other in the environment of the program ANSYS. The basis for their confrontation are the values of the vertical displacement, vertical speed and vertical acceleration.

Model B is created according to the transition area of the southern portal of the Tunnel Turecky vrch using the real values of the static deformation modulus of the trackbed and the material characteristics of the particular components of the line structure. The model shows that the currently built transition area is relevant. It is for that reason that the transition area significantly absorbs the dynamic effects of the passing trains, which is also proved by the comparison with the initial model $\mathrm{A}$. This model was created to be compared to the case when there is no transition area applied on the line.

Taking into account the defects occurrence in the track geometry of the transition areas (they were recorded within the diagnostics by the manual measuring trolley $K R A B^{T M}$-Light, measuring car of ZSR and stated by the geodetic survey of the layout of the track), other models were created in order to optimise the existing transition area. The models were implemented with the aim to create the transfer of vehicles between the two areas of different stiffness as fluent as possible. The optimisation of the transition area will decrease the dynamic effects on the line structure. In this way, the defects occurrence in the track geometry, which results in the necessity to realise the costintensive corrective actions related to the lockouts, diminishing the attractiveness and competitiveness of the rail transport, will be eliminated or minimized.

The improvement of the transfer between the two areas of different stiffness should be originally numerically modelled by means of three models, which would improve the existing transition area of another structural element. These are: a model with a couple of stiffening rails, a model applying the under sleeper pads and a model with the stabilization of the railway ballast of the transition area in the shape of reinforced concrete tub by chemical binders (the so called bonding of the railway ballast). Finally, only the first two cases were modelled, due to the lack of the input data and the large variance of values of the material characteristics of the chemically stabilized railway ballast.

Despite the initial expectations, the application of the stiffening rails was not considered as a significant improvement. The placement of the stiffening rails into the track brought the lowering of the values of the vertical displacement and also the vertical speed, but only minimally. Application of the under sleeper pads has proved to be an interesting way of optimisation of the transition area. The placement of the pads, $10 \mathrm{~mm}$ thick, in the whole length of the transition area (model D) brought the relevant improvements. However, there were obvious restraints in the most problematic place - between the last sleeper in the slab track and the first sleeper in the transition area in the shape of reinforced concrete tub. Exactly at those places - in the first metres of this transition area in the contact with the slab track -the defects were detected by the diagnostics resulting in the necessity to carry out the corrective actions. This knowledge led to the optimisation of model D. In this model, the section with the under sleeper pads was partially moved forward into the slab track, a part of the pads was then situated in the area of the slab track and a part in the transition tub. It was exactly this model, which created the most fluent transfer between the areas concerned and it seems to be the most convenient one. However, in the case of the application directly on the line, it would be necessary to resolve technically 
and technologically the embedding of the under sleeper pads under the double block sleepers of a monolithic construction directly with the producer (or supplier) of the slab track system.

Based on the realised numerical modelling, it can be stated that the best way to optimise the existing transition area in the area of the southern portal of the Tunnel Turecky vrch is to apply the under sleeper pads in the section of the transition area in the shape of reinforced concrete tub. The application of the under sleeper pads in the transition area seems to be beneficial in case of the future applications of the slab track systems within the railway infrastructure of the Slovak Republic. However, the most efficient would probably be the displacement of the section with the under sleeper pads also into a part of the slab track section.

The under sleeper pads can be globally evaluated as a relevant structural element for the optimisation of the transition areas between the slab track and the ballasted track. However, before their direct implementation into the line it would be necessary to verify this structure by realization of set of numerical modelling with different types of pads and a different section length with pads. It would be desirable to verify the section combination with different types of under sleeper pads, as well, which would be coherent in the transition area or which would partially reach into the slab track section. Subsequently, it would be desirable to verify the results of the numerical modelling on a test section with a real railway operation.

\section{Acknowledgement}

The paper contains results of the grant VEGA 1/0275/17 "Application of numerical methods to define the changes of geometrical track position”.

\section{References}

[1] SESTAKOVA, J.: Quality of Slab Track Construction - Track Alignment Design and Track Geometry. Civil and Environmental Engineering, 11(1), 2-9, 2015. https://doi.org/10.1515/cee-2015-0001

[2] IZVOLT, L., IZVOLTOVA, J., HODAS, S., MECAR, M., PISCA, P., SESTAKOVA, J., SMALO, M.: Monitoring of Sections of a Non-Conventional Constructions of the Railway Superstructure and the Transition Areas - 9th and 10th Stage. ZSR Modernization of Railway Track Nove Mesto nad Vahom - Puchov, km 100.500 to 159.100, part 24-32-01 Nove Mesto - Trencianske Bohuslavice (in Slovak). Department of Railway Engineering and Track Management, Faculty of Civil Engineering, University of Zilina, Zilina, 2016.

[3] SESTAKOVA, J., MECAR, M.: Evaluation of Track Design and Track Geometry of the Track with Unconventional Structure of Railway Superstructure. XXIV. R-S-P seminar Theoretical Foundation of Civil Engineering (24RSP) (TFoCE 2015), Procedia Engineering, 111, 709-716, 2015. https://doi.org/10.1016/j.proeng.2015.07.136

[4] SMALO, M., IZVOLT, L.: Assessment of Track Quality in Trial Test Sections by Spot and Continuous Method. Communications - Scientific Letters of the University of Zilina, 17(4), 28-33, 2015.

[5] IZVOLTOVA, J., VILLIM, A., PISCA, P.: Analysis of Height Changes of Ballastless Track. Geodesy, Cartography and Geographic Information System. Proceedings of VIII. International conference Tatranske Matliare, Slovakia, 2014.

[6] ZIMMERMANN, H.: Calculation of the Railway Superstructure. Verlag V. Ernst \& Sohn, Berlin, 1941.

[7] Normative DB Netz: Requirements on Ballastless Track Construction - 4th edition (in German), 2002.

[8] Normative SZDC S9: Ballastless Track (in Czech), 2012.

[9] SHAHRAKI, M., WARNAKULASOORIYA, CH., WITT, K. J.: Numerical Study of Transition Zone between Ballasted and Ballastless Railway Track. Transportation Geotechnics, 2(3), 58-67, 2015. https://doi.org/10.1016/j.trgeo.2015.05.001

[10] SHAN, Y., ALBERS, B., SAVIDIS, S. A.: Influence of Different Transition Zones on the Dynamic Response of Track-Subgrade Systems. Computers and Geotechnics, 28(48), 21-28, 2013. https://doi.org/10.1016/j.compgeo.2012.09.006 